\title{
Radon Monitoring and Early Low Background Counting at the Sanford Underground Laboratory
}

\author{
K.J. Thomas ${ }^{\mathrm{a}}$, D.-M. Mei ${ }^{\mathrm{a}}$, J. Heise ${ }^{\mathrm{b}}$, D. Durben ${ }^{\mathrm{c}}$, R. Salve ${ }^{\mathrm{d}}$ \\ ${ }^{a}$ The University of South Dakota, Vermillion, SD 57069, USA \\ ${ }^{b}$ Sanford Laboratory at Homestake, Lead, SD 57754, USA \\ ${ }^{c}$ Black Hills State University, Spearfish, SD 57799, USA \\ ${ }^{d}$ Lawrence Berkeley National Lab, Berkeley, CA 94720, USA
}

\begin{abstract}
Radon detectors have been deployed underground at the Sanford Underground Laboratory at the site of the former Homestake Mine in Lead, SD. Currently, no radon mitigation measures are in place in the underground environment, and the continuing evolution of the facility ventilation systems has led to significant variations in early airborne radon concentrations. The average radon concentration measured near the primary ventilation intake for the $4850-\mathrm{ft}$ level (Yates shaft) is $391 \mathrm{~Bq} / \mathrm{m}^{3}$, based on approximately 146 days of data. The corresponding average radon concentration near the other main ventilation intake for the $4850-\mathrm{ft}$ level (Ross shaft) is $440 \mathrm{~Bq} / \mathrm{m}^{3}$ based on approximately 350 days of data. Measurements have also been collected near the 1250-ft level Ross shaft, with average radon concentrations at $180 \mathrm{~Bq} / \mathrm{m}^{3}$. Secondary factors that may increase the baseline radon level underground include the presence of iron oxide and moisture, which are known to enhance radon emanation. The results of the current radon monitoring program will be used for the planning of future measurements and any potential optimization of ventilation parameters for the reduction of radon in relevant areas underground.
\end{abstract}

Keywords: Homestake Mine, Sanford Underground Laboratory, radon

PACS: 29.40.-n, 23.40.-s, 95.35.+d

\section{INTRODUCTION}

Long-term radon monitoring is being conducted at the Homestake Mine for future planning and design for the Sanford Underground Laboratory and DUSEL. Starting in the fall of 2009, three Saphymo (formerly Genitron) AlphaGuard radon detectors were placed at locations along the primary ventilation path underground as shown in Figure 1 to give horizontal and vertical radon comparisons along the ventilation paths. Sites chosen included the 1250L Ross Station, 4850L Ross Station, and the 4850L Yates Station (the local notation uses 4850L to indicate the 4850-ft. level, for example). The goal of the monitoring project is to track changes in the radon levels underground as improvements and modifications are made to the ventilation system during the early phases of underground activity. It is the hope that the understanding derived from these measurements will be useful when it comes to optimizing the ventilation scheme in the future for the control of radon underground.

Relevant factors that affect radon levels underground in the Homestake mine include ventilation, local geology, moisture, and the presence of iron oxide. However, the dominant factor recorded during the monitoring period is the ventilation. As low-radon surface air is brought down into the mine, it dilutes and purges the radon-laden air out exhaust shafts. As a result, changes in ventilation cause fluctuations in radon concentrations. It should be noted that the ventilation system at this time is not modified or changed in any way for radon monitoring at all since its current priority is ventilation alone and that it is currently operating at only around $30 \%$ of its historical capacity. Secondary factors related to the emanation of radon from the rock are not observable due the dynamic nature of the radon due to the ventilation system. These secondary factors include aspects of local geology such as composition, radioisotope distribution in rock grains, and rock porosity that may result in variations in radon emanation from location to location underground. In addition, the presence of water and iron oxide may enhance the emanation of radon to some degree in areas that were recently underwater between decommissioning and reopening of the mine. 


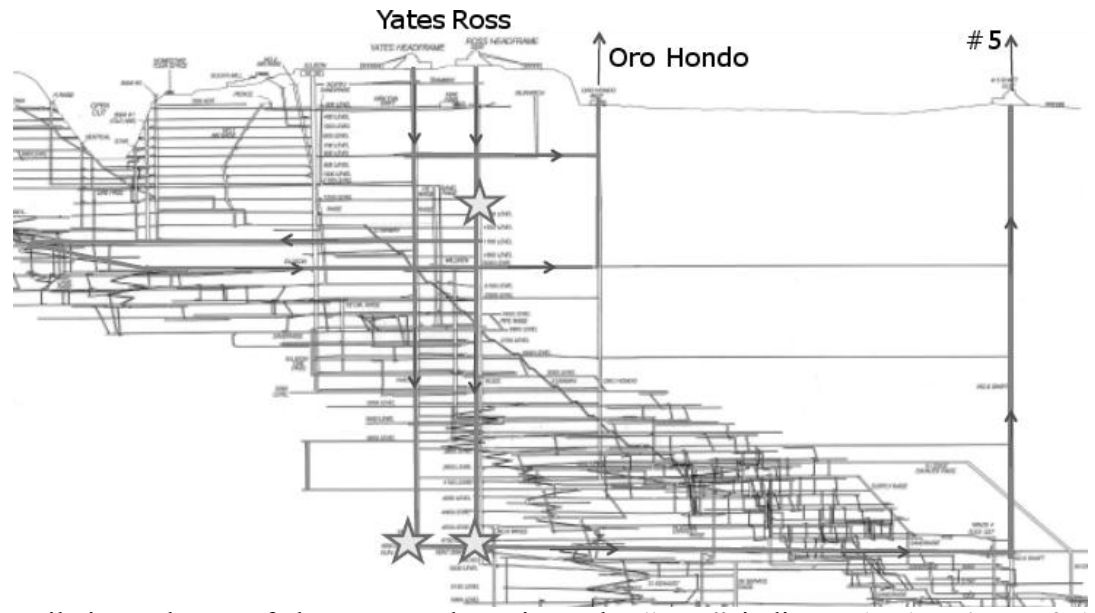

FIGURE 1. Basic ventilation scheme of the Homestake Mine. The "stars" indicate the locations of the AlphaGuard radon detectors at the 1250L and 4850L Ross stations, and the 4850L Yates station. Exhaust fans at the top of the Oro Hondo and \#5 Shafts draw air out of the mine such that intake air is taken in down along the Ross and Yates Shafts. At this time much of the ventilation capacity is done through the Oro Hondo while the \#5 Shaft is reserved for auxiliary use.

\section{LONG TERM RADON MONITORING}

Of the data collected, there are around 13 months of radon levels recorded at the 1250L Ross Station, 10 months at the 4850L Ross Station, and around 5 months at the 4850L Yates station. Underground construction activities have caused some interruptions in the monitoring at the 4850L locations. Since September of 2009, the 1250Land 4850L Ross stations have total averages of $180 \mathrm{~Bq} / \mathrm{m}^{3}$ and $440 \mathrm{~Bq} / \mathrm{m}^{3}$, respectively. The 4850LYates Station has a total average of $391 \mathrm{~Bq} / \mathrm{m}^{3}$. It should be noted that the large upswings in radon levels due to ventilation changes at these locations are included in their total averages. Summary plots of average monthly, weekly, and daily radon concentrations are shown in Figures 2 and 3.

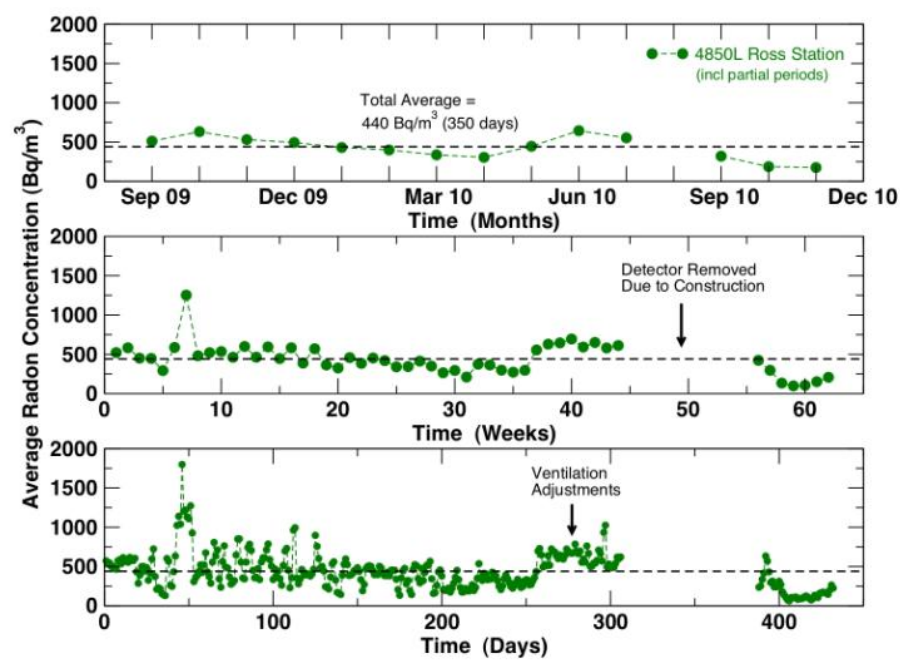

FIGURE 2. Continuous radon levels at the 4850L Ross station from September 2009 to October 2010. The radon levels are displayed in averages of monthly, weekly, and daily radon levels to reveal different trends such as the rapid ventilation shifts responsible for the structure in the daily averages. The detector was removed for a period of time due to construction for a couple months during the summer of 2010. 


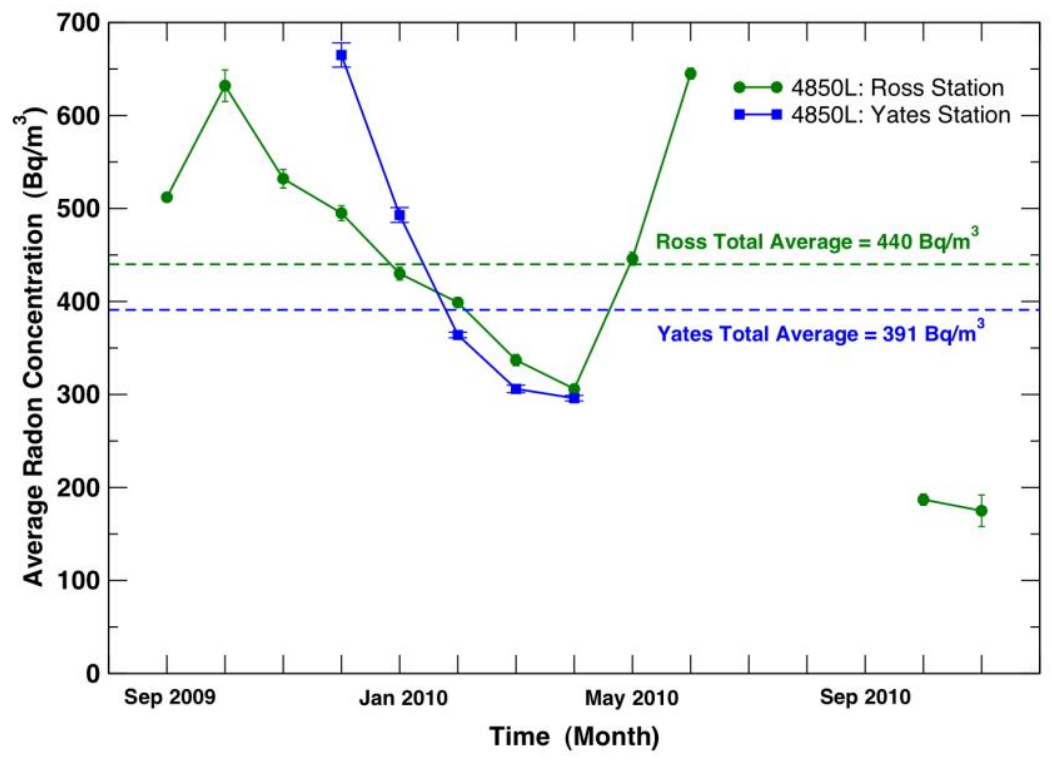

FIGURE 3. Monthly averages at the 4850L locations, based on 350 days of data at the Ross Station and 146 days at the Yates Station. Construction activities recently interrupted the monitoring during the summer of 2010.

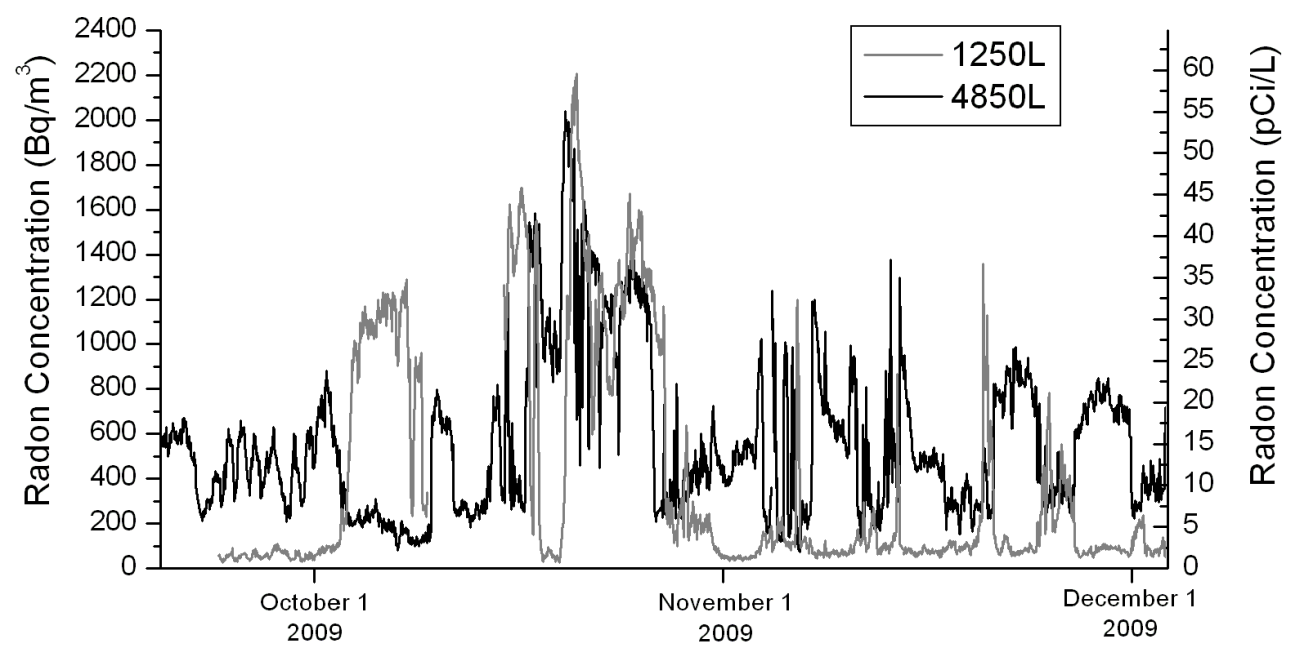

FIGURE 4. Comparison of the Ross stations at the 1250L and 4850L. This reveals the dynamic nature of the ventilation system. An example of a clear ventilation shift is evident in early October of 2009 in which the airflow in the Ross Shaft reverses. Suddenly, instead of sampling low-radon intake air, exhaust air from deeper parts of the mine flows past the 1250L Ross Station; meanwhile, the 4850L Ross Station stabilized with a lower radon concentration. Such exchanges are shared across the three sampling locations.

\section{Radon and Ventilation}

Since radon levels are low in the surface atmosphere (around $10 \mathrm{~Bq} / \mathrm{m}^{3}$ ), the introduction of the surface air is important as a first step in reducing radon at underground locations. However, increased air movement in a particular location does not necessarily mean decreased radon levels, since the amount of time that air has been underground is also important. For instance, the 1250L Ross Station typically has a pretty low baseline radon level 
of around $100 \mathrm{~Bq} / \mathrm{m}^{3}$ in comparison with the $4850 \mathrm{~L}$ Ross Station, which typically has air that has been underground longer, meaning that the air it samples has had the opportunity to collect or flush out more radon from other areas. Note the first week of October in Figure 4, where the radon level at the Ross station on the 1250L jumps to over $1200 \mathrm{~Bq} / \mathrm{m}^{3}$ and the $4850 \mathrm{~L}$ Ross station drops and stabilizes to around $250 \mathrm{~Bq} / \mathrm{m}^{3}$. The exchange is an event in which the ventilation coming down the Yates Shaft to the 4850L overpowers the ventilation coming down the Ross Shaft and forces it into an up-cast scenario. As shown in the ventilation scheme in Figure 1, the reason for the Ross Shaft being susceptible to air flow direction reversals may be because much of its capacity is drawn horizontally on shallower levels and out the Oro Hondo shaft. When the Ross Shaft switches to up-cast, the 1250L detector suddenly begins measuring the exhaust air from deeper levels rather than the input "clean" air from the surface. Several more of these ventilation events are evident in Figure 4. Although not pictured, the 4850LYates Station monitoring site also has ventilation induced radon shifts that coincide with those at the 1250L and 4850L Ross stations. At this point, some of the ventilation shifts are understood or accounted for, but many are not. The 4850L Yates Station is much less chaotic in terms of radon swings compared to the Ross stations, likely due to the vulnerability of air reversals on the Ross Shaft. Factors that could account for fluctuations in the ventilation include the opening and closing of air doors, underground activities, the direction of winds at the surface intake shafts, and perhaps other less obvious features. The group is working with the ventilation technicians at the Sanford Lab to identify and understand some of the results of the radon monitoring.

As seen in Figure 3, the overall average monthly radon levels at the 4850L Ross Station are much lower during the fall of 2010 as compared to the preceding year. These monthly averages include the large upswings in radon concentrations that occur due to ventilation events. The cause of this overall reduction in monthly radon concentration averages could be a result of a few factors. The Sanford Lab has been adding air-doors in various locations, which affects the control of airflow to deeper levels and prevents the bleeding-off of surface ventilation to unwanted areas. They have also made modifications and tweaked the fan speeds at the top of the exhaust shafts. In addition, these changes to the ventilation system may also be stabilizing the airflow at these particular locations, which is related to the overall reduction in frequency of the large radon upswings as shown in the early half of the daily averages portion of Figure 2. Overall, the Yates Station has been much more stable than the Ross Station-its upswings are almost cyclical as seen in the radon trend in Figure 5, without the dramatic upswings of radon seen on the Ross Shaft locations. At this point, it is too early to tell if there will be any seasonal variance to the underground radon since the ventilation system is so dynamic and has undergone several changes.

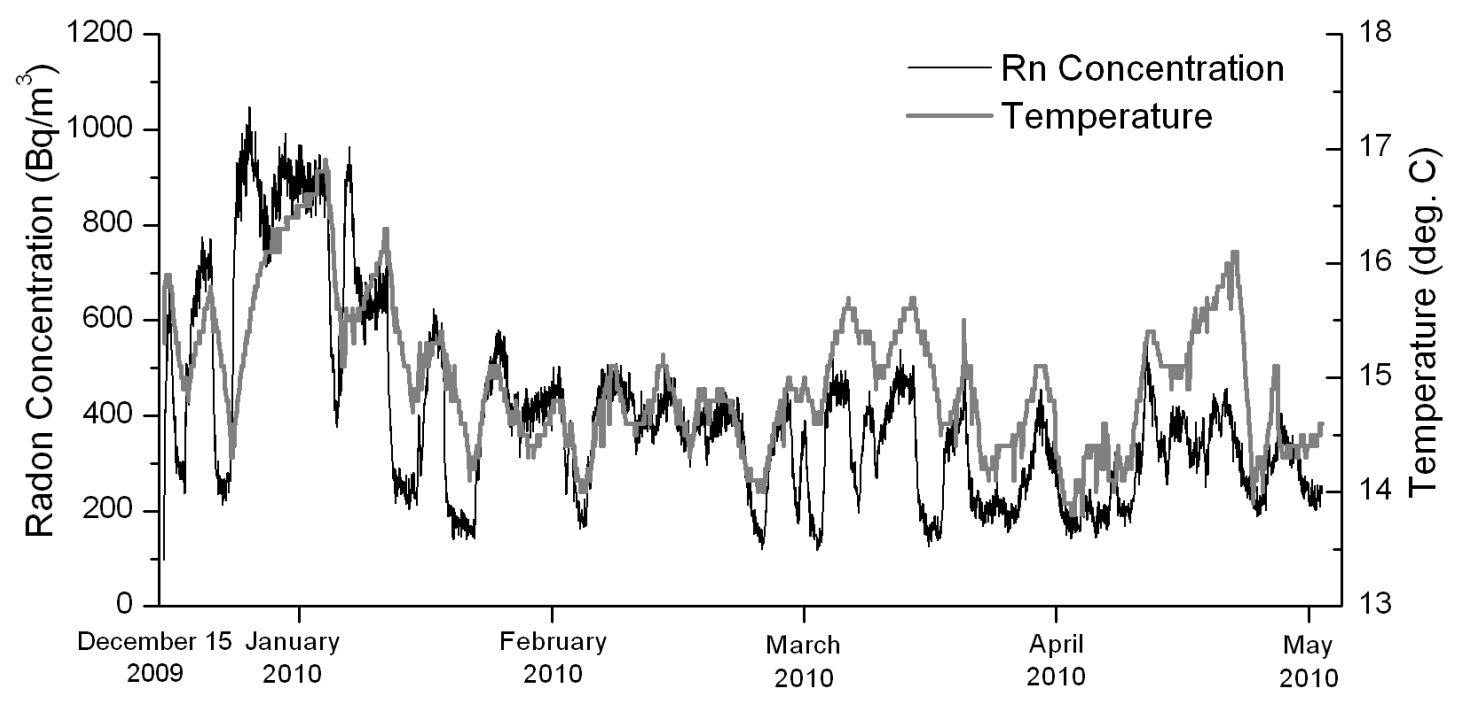

FIGURE 5. Radon and Temperature at the 4850L Yates Station. As shown above, lower temperatures are related to lower radon levels at this location, likely due to a larger fraction of colder surface air traveling to the measurement location more directly. 


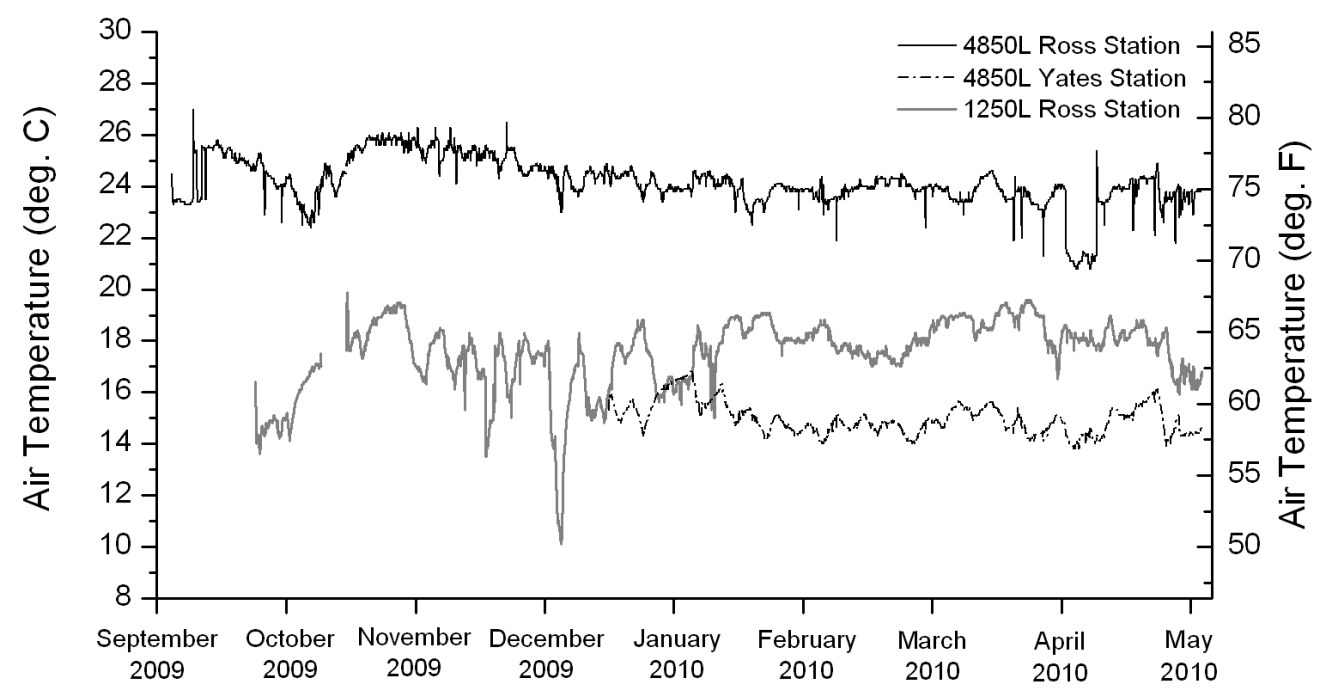

FIGURE 6. Air temperatures at the three measurement locations. The 4850L Yates Station is significantly cooler than the 4850L Ross Station, which indicates it receives a more direct supply of cooler surface air.

\section{Radon and Air Temperature}

Comparison of radon levels with some of the other environmental data recorded by the radon detectors can produce additional remarks about the ventilation system concerning how direct the path of the surface air is to a particular location. In Figure 5, temperature variations shown side by side with fluctuations in radon levels also reinforce the scenario in which low-radon surface air will reduce radon levels. In general during the pictured sampling period over fall and winter, air from the surface is cooler than the temperatures of the rock underground, which could allow for the determination of increases or decreases of direct surface air ventilation to a particular location. Therefore, low levels of radon correlate to lower air temperatures due to a larger fraction of cooler surface air passing in a more direct manner to the test location. On the other hand, raises in air temperature also correlate to raises in radon levels, which is due to warmer, radon-laden air that has spent a longer amount of time underground. Lower temperatures at the 4850L Yates Station compared to the than the 4850L Ross Station, as seen in Figure 6, would imply that the Yates Station on average receives a more stable, direct proportion of surface air. Therefore, temperature variations may detail changes in how direct the airflow is from the surface to the measurement location. This supports the use of air temperature as a tool to indicate the path length of the air introduced underground. Of course, the effectiveness of this method will vary seasonally due to variations in seasonal surface air temperature and from location to location because of variations in rock temperature across different depths underground. It should also be said that the measurement of the temperature on these devices is not completely understood and may be affected by other circumstances such as nearby equipment, contractor activity, and insulating effects of protective enclosures.

\section{Iron Oxide and Radon Emanation}

One of the interesting factors that may impact radon emanation at the Homestake Mine involves the presence of iron oxide on rock surfaces that were recently submerged in water. The formation of metal oxides can impact radon emanation in two ways. First, radionuclides such as uranium and radium have been observed previously to sorb or co-precipitate in metal oxide layers [1]. Second, being a weathering process on rock, it enhances the surface porosity of rock layers which facilitates radon emanation and diffusion into the air. Because of the significant presence of iron oxide underground on levels submerged in water below the 4530L, the group arranged for a sample to be tested at the Lawrence Berkeley National Laboratory Low Background Facility (LBNL LBF) in March of 2010. The dewatering process at Homestake involves cleansing the pumped-out water before releasing it into the environment. As a result, a filtration system on the surface collects concentrated iron oxide sludge. Around $2 \mathrm{~kg}$ of this iron oxide 
sludge sample was sent to LBNL counting facility. Preliminary results indicate that uranium and thorium chains are not in secular equilibrium not because of radon emanation, but rather because of the radium migration into the iron oxide coating. For example in sample 3/11/10-2, counting of the early uranium series indicated the ${ }^{238} \mathrm{U}$ content was $1.2 \mathrm{ppm}$ while the late half of the series indicated $14 \mathrm{ppm}$; whereas the thorium series indicated $\mathrm{a}^{232} \mathrm{Th}$ level of 45 ppm in the early chain and only $12 \mathrm{ppm}$ in the latter portion of the chain [2]. In secular equilibrium, one would expect to find agreement on the initial $\mathrm{U}$ or Th content at any part of the chain. This supports the idea that radium has leeched out of the rock during the formation of the iron oxide, because of the geochemical enrichment of ${ }^{228} \mathrm{Ra}$ in the middle of the uranium chain and ${ }^{228} \mathrm{Ra}$ in the early thorium chain. In comparison, some common Homestake rock samples have $U$ and $T h$ content in the range of 0.08-0.5 ppm $U$ and 0.19-0.3 ppm Th [3]. Therefore, a sample of this iron oxide is believed to be able to emanate more radon than the host rock it formed upon since it is significantly enriched in radium content. At this point, the radon measurements underground do not reflect any information regarding the iron oxide since ventilation dominates the features in the radon monitoring, so the role of iron oxide may only affect radon on a baseline level. Further studies are being conducted on the iron oxide at the University of South Dakota regarding radon emanation through further use of low background counting and radon emanation measurements along with additional counting at the LBNL LBF.

\section{Radon Summary and Plans}

In summary, the dominant factor relevant to radon concentrations underground at the Homestake Mine is the amount of direct surface air ventilation available to a particular location under the dynamic ventilation system, which is currently operating around $30 \%$ of its historical capacity. The introduction of surface air ventilation reduces radon levels by diluting or flushing out radon laden air. Intermittently some areas end up with higher than normal radon levels due to dirty 'exhaust' air being pushed into certain areas, such as the air reversals shown by the $4850 \mathrm{~L}$ and 1250L Ross stations. Other factors that may play a secondary role in raising the baseline radon level underground include the presence of iron oxide from 4530L and below, which was recently underwater. Recent counting results from LBNL on a sample of iron oxide sludge confirm that the iron oxide may be relevant to the radon emanation underground, but the effect of which is unknown since it is limited as a secondary baseline factor beneath the substantial ventilation fluctuations. The airflow underground can fluctuate drastically from changes in ventilation in both strength and direction. Thus far, measurements indicate that overall the ventilation is much more stable compared to the early few months sampled due to large radon 'spikes' occurring less frequently . Overall reductions in average radon levels have been exhibited in the monthly measurements; in particular at the 4850L Ross Station that has averaged $195 \mathrm{~Bq} / \mathrm{m}^{3}$ during the fall of 2010 , which is consistent with temporary ventilation effects. However, more study is needed to control and stabilize such conditions. It should also be noted that as the ventilation is modified, such as the installation of new air doors and fan adjustments, the behavior of radon underground at various locations will also continue to change due to its direct relationship with the ventilation.

As for future plans, the continuation of these measurements are planned in an effort to further isolate and determine relationships between the ventilation system of the Homestake Mine and radon levels underground. As more detectors become available, they will be added in various locations along the main ventilation paths. More details are needed to characterize the ventilation system, which is very complex. Continuous air speed monitors are being considered to track ventilation changes alongside the long term radon measurements. Currently, there are plans to more accurately map and understand the airflow underground. By doing so, it may be possible to determine how much surface air is being lost to shallower, unused levels that effectively leech the clean surface airflow away from the deeper levels. Identification of parasitic airflows such as these may allow for recommendations for the installation of additional air doors at various locations to optimize airflow where desired. Additional measurements of iron oxide and rock samples from the Homestake underground are also planned with their relevance to increased radon emanation and dust radio-contamination.

\section{LOW BACKGROUND COUNTING AT THE SANFORD LABORATORY}

Low background counting and materials purity are crucial to the success of underground experiments. As a result, there is an effort to establish some early screening capacity at the Homestake Mine to support underground experiments. A limited space at the Sanford Laboratory located in the Davis Cavern on the 4850Lwill host the first screening facility at Homestake. At this time the University of South Dakota will provide the first germanium counting station underground tentatively in the Fall of 2011, followed by two to three more counting stations over the following years under various funding sources. 


\section{ACKNOWLEDGMENTS}

Special thanks to: Connie Giroux, Tom Trancynger, Brian Lowery, Jared Thompson, Chad Ronish, Kara Keeter, Peter Lemke, Kristal Lemke, Jon Crosswait, Reggie Walters, Kevin Lesko, Al Smith, Yuen-Dat Chan, Richard Gaitskell, Simon Fiorucci, Sanford Laboratory, and the South Dakota Space Grant Consortium. This work was also partially supported by the U.S. Department of Energy and LBNL under Contract No. DE-AC02-05CH11231.

\section{REFERENCES}

1. R.R. Schuman and L.C.S. Gundersen. "Geologic and climatic Controls on the Radon Emanation Coefficient.” Environment International 22, Suppl. 1, S439-S446 (1996).

2. A.R. Smith. Private communication, 8/31/10.

3. W. Roggenthen and A.R. Smith. "Uranium, Thorium, Potassium Contents of Materials in the Homestake Underground, Lead SD.” 2008 AGU Fall Meeting, San Francisco, CA. 


\section{DISCLAIMER}

This document was prepared as an account of work sponsored by the United States Government. While this document is believed to contain correct information, neither the United States Government nor any agency thereof, nor The Regents of the University of California, nor any of their employees, makes any warranty, express or implied, or assumes any legal responsibility for the accuracy, completeness, or usefulness of any information, apparatus, product, or process disclosed, or represents that its use would not infringe privately owned rights. Reference herein to any specific commercial product, process, or service by its trade name, trademark, manufacturer, or otherwise, does not necessarily constitute or imply its endorsement, recommendation, or favoring by the United States Government or any agency thereof, or The Regents of the University of California. The views and opinions of authors expressed herein do not necessarily state or reflect those of the United States Government or any agency thereof or The Regents of the University of California.

Ernest Orlando Lawrence Berkeley National Laboratory is an equal opportunity employer. 